\title{
Structural, Morphological, and LPG Sensing Properties of Al-Doped ZnO Thin Film Prepared by SILAR
}

\author{
Shampa Mondal, Shatabda Bhattacharya, and P. Mitra \\ Department of Physics, The University of Burdwan, Golapbag, Burdwan, West Bengal 713104, India \\ Correspondence should be addressed to P. Mitra; mitraparthal@rediffmail.com
}

Received 19 May 2013; Accepted 9 October 2013

Academic Editor: Jun Zhang

Copyright ( 2013 Shampa Mondal et al. This is an open access article distributed under the Creative Commons Attribution License, which permits unrestricted use, distribution, and reproduction in any medium, provided the original work is properly cited.

\begin{abstract}
Undoped and aluminum doped zinc oxide (AZO) thin films were deposited on glass substrates by successive ion layer adsorption and reaction (SILAR) technique from ammonium zincate complex. The thin films are characterized by X-ray diffraction (XRD) and scanning electron microscopy (SEM) for their structural and morphological studies. Both undoped and Al-doped film show strong preferred c-axis orientation. The texture coefficient (TC) of the film along (002) direction increases due to Al incorporation. SEM micrograph shows round shaped particles for pure ZnO. However AZO films show particles with off spherical shape and compact interconnected grains. Sensitivity of the film in presence of $80 \%$ LEL (lower explosive limit) of LPG increases with temperature and is maximum at $325^{\circ} \mathrm{C}$. Significantly high sensitivity of $87 \%$ with reasonably fast response was observed for $1 \% \mathrm{Al}$-doped $\mathrm{ZnO}$ (AZO) film in presence of $1.6 \mathrm{vol} \% \mathrm{LPG}$ at $325^{\circ} \mathrm{C}$.
\end{abstract}

\section{Introduction}

Zinc oxide $(\mathrm{ZnO})$ is a promising material for gas sensor application. Thin films of $\mathrm{ZnO}$ are important for detecting toxic pollutant gases, combustible gases and organic vapors. The performance and efficiency of thin film-based devices are determined strongly by the structural, morphological, and electrical properties of the component films. These properties are determined by the process parameters during film growth as well as by the presence of impurities and defects in the films. AZO films have got potential applications in solar cells, solid-state display devices, optical coatings, heaters, defrosters, and chemical sensors [1,2]. Doping with $\mathrm{Al}$ is primarily done to achieve high transparency, stability, and high conductivity and also because it enhances the gas-sensing properties of the $\mathrm{ZnO}$ thin films, which have immensely important industrial and domestic applications for detecting hazardous gases, including LPG [3]. Accordingly, synthesis of polycrystalline AZO thin films has been widely carried out using different techniques such as ultrasonic chemical vapor deposition [4], spray pyrolysis [5], pulsed laser deposition [6], DC reactive sputtering [7], RF magnetron sputtering [8], helicon-wave excited plasma (HWP) deposition [9], spin coating [10], sol-gel [11], and chemical beam deposition [12] among many others.

Although the conventional physical techniques give uniform and compact films with high transparency, they are usually very expensive and are difficult to expand to large scale. The desired characteristics of a sensor material need to be balanced with the processing costs for practical applications. Low-temperature chemical techniques involving aqueous route (from solutions) on the other hand are versatile, simple, and cost-effective as compared with vapor-phase techniques. Among the various chemical techniques, one of the less used and less studied chemical techniques is SILAR. In SILAR technique, a substrate is dipped alternately into beakers containing aqueous solutions (cationic and anionic) for the reaction to take place at the substrate surface. The substrate can be introduced into various reactants for a specific length of time depending on the nature and kinetics of the reaction. The immersion-reaction cycle can be repeated for any number of times, limited only by the inherent problems associated with the deposition technique and the substrate-thin film interface. The technique is called SILAR (successive ion layer adsorption and reaction) since it involves adsorption of a layer of complex ion on the substrate followed by 
reaction of the adsorbed ion layer. Since the synthesis can be carried out under mild conditions and at lower processing temperatures, implantation of dopant at low temperatures may be particularly suitable by this method.

The present study deals with the preparation and characterization of undoped and $\mathrm{Al}$-doped $\mathrm{ZnO}$ thin films on glass substrate by SILAR and their gas sensing characteristics in presence of LPG. Al incorporation in $\mathrm{ZnO}$ lattice is always limited $[13,14]$. In the present work $1 \%$ AZO films have been prepared. Earlier Rakhshani [15] reported preparation of AZO films by SILAR using sodium zincate complex. However use of sodium complex always introduces highly mobile sodium ions in the films [16] which can be detrimental for their practical applications. The objective of this work was to synthesize AZO films from ammonium zincate complex in order to eliminate the incorporation of highly mobile sodium ions in the films and to study the application potentiality of the films as LPG sensor.

\section{Materials and Methods}

Pure and Al-doped $\mathrm{ZnO}$ thin films were deposited on clean glass substrates by SILAR technique which involved dipping of the substrate in ammonium zincate complex kept at room temperature and hot water bath kept near boiling point. The ammonium zincate bath, used for deposition, was prepared by adding ammonium hydroxide ( 25\% pure ammonia solution; Merck, Mol. Wt. $17.03 \mathrm{~g} / \mathrm{mol}$, density 0.91$)$ to an aqueous solution of zinc acetate dihydrate (Merck, India). The $\mathrm{pH}$ of the zincate solution measured in a Systronics $\mathrm{pH}$ meter (Model 335) was 10.80.

The details of pure $\mathrm{ZnO}$ film deposition from ammonium zincate bath have been reported earlier [16-18]. Briefly, a precleaned substrate (microscopic glass slide) is alternately dipped in zinc complex kept at room temperature and hot water bath maintained at $\sim 95-98^{\circ} \mathrm{C}$. One complete set of dipping involves dipping the substrate in each bath for two (2) seconds. 50 dippings were performed for the present experiment. 1\% $\mathrm{Al}$-doped $\mathrm{ZnO}$ film was prepared by adding aluminium chloride hexahydrate $\left(\mathrm{AlCl}_{3} \cdot 6 \mathrm{H}_{2} \mathrm{O}\right.$, Merck) as the source of dopant and was added in requisite amount in the zincate bath. All the deposited films were white and homogeneous. After deposition, peel-off test was conducted to confirm the adhesivity of the coated films on glass substrates which showed well adherent films on the substrate. The thicknesses of the films were measured by the weight differencedensity consideration [19] method using an electronic high precision balance. The thickness for pure $\mathrm{ZnO}$ film was $\sim 0.8 \mu \mathrm{m}$ and it was $\sim 0.96 \mu \mathrm{m}$ for Al-doped film indicating higher growth rate due to $\mathrm{Al}$ incorporation.

Structural analysis of the deposited films was carried out using Philips PW 1830 X-ray diffractometer with $\mathrm{CuK}_{\alpha}$ radiation $(\lambda=1.5418 \AA$ ) as $\mathrm{X}$-ray source at $40 \mathrm{kV}$ and $20 \mathrm{~mA}$. The experimental peak positions were compared with the standard JCPDS files and the Miller indices were assigned to the peaks. Scanning electron microscopy (FEI FEG Nova 600) was used to study the variation of surface morphology and to illustrate the formation of crystallites on the film surface. EDX analysis was carried out to check the incorporation of $\mathrm{Al}$ in the doped film. High conducting silver (Ag) paste was used to make ohmic contacts on both the ends of the films to carry out electrical measurements on them. Approximately $20 \mathrm{~mm}$ long silver contacts, separated by $5 \mathrm{~mm}$, were made on the films for electrical measurements. The width of the electrodes was approximately $1 \mathrm{~mm}$. The film was mounted on a home-made two-probe assembly placed into a ceramic tube which was inserted coaxially inside a resistance-heated furnace. The electrical resistance of the films was measured before and after exposure to LPG using a Keithley System Electrometer (Model: 6514). The sensitivity of the film was determined at different operating temperatures in the range $250-375^{\circ} \mathrm{C}$ in presence of LPG in air. Commercially available calibrated mixtures of LPG were used for this purpose. Before exposing to LPG, the film was allowed to equilibrate at each operating temperature for 30 minutes. The percent sensitivity was estimated by measuring the percent reduction of resistance in presence of the test gas. Thus if $R_{\text {air }}$ and $R_{\text {gas }}$ represent the equilibrium sample resistance in ambient air and under test gas, respectively, the percent sensitivity $(\mathrm{S} \%)$ can be expressed as

$$
S \%=\frac{R_{\mathrm{air}}-R_{\mathrm{gas}}}{R_{\mathrm{air}}} \times 100 .
$$

\section{Results and Discussions}

Figure 1 shows the X-ray diffraction (XRD) spectra of undoped and $1 \% \mathrm{Al}$-doped $\mathrm{ZnO}$ films. The films were annealed at $350^{\circ} \mathrm{C}$ for $2 \mathrm{hr}$ in air prior to structural characterization. The diffraction pattern for pure $\mathrm{ZnO}$ is shown in Figure 1(a), while Figure 1(b) shows the diffractogram for $1 \%$ AZO. The diffraction angle $2 \theta$ was scanned in the range $20^{\circ}$ to $70^{\circ}$. The $2 \theta$ variation was employed with a 0.05 degrees step and a time step of 1 second. Intensity in arbitrary units is plotted against $2 \theta$ in Figure 1. It is seen from Figure 1(a) that peaks appear at $31.75^{\circ}, 34.389^{\circ}, 36.205^{\circ}, 47.434^{\circ}, 56.576^{\circ}$, and $62.855^{\circ}$. All the peaks are in good agreement with the joint committee on powder diffraction standard (JCPDS) data belonging to hexagonal $\mathrm{ZnO}$ structure [20]. The corresponding reflecting planes are (100), (002), (101), (102), (110), and (103), respectively. Apart from $\mathrm{ZnO}$ characteristic peaks, no phase corresponding to aluminum or other aluminium compounds was observed in the XRD patterns. This observation suggests that the films do not have any phase segregation or secondary phase formation as well as $\mathrm{Al}$ incorporation into $\mathrm{ZnO}$ lattice. The (002) peak appears with maximum intensity in undoped and Al-doped films indicating preferred orientation of the crystals along c-axis that is perpendicular to the substrate. The other peaks corresponding to (100), (101), (102), (110), and (103) are present with low relative intensities.

Quantitative information concerning the preferential crystal orientation can be obtained from the texture coefficient, TC, defined as [21]

$$
\mathrm{TC}(h k l)=\frac{I(h k l) / I_{o}(h k l)}{(1 / n) \sum_{n} I(h k l) / I_{o}(h k l)},
$$




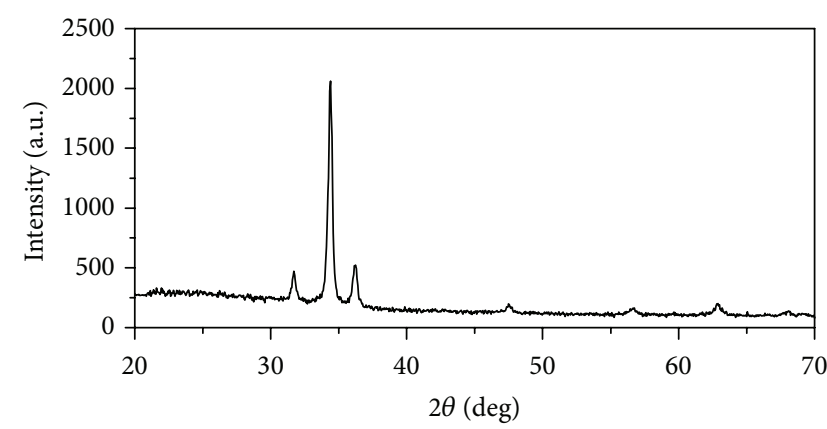

(a)

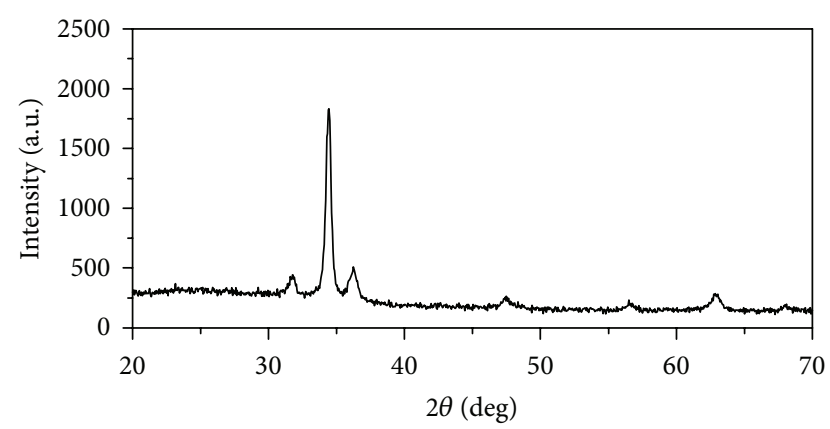

(b)

Figure 1: X-ray diffraction pattern of (a) undoped $\mathrm{ZnO}$ and (b) $1 \% \mathrm{AZO}$ film.

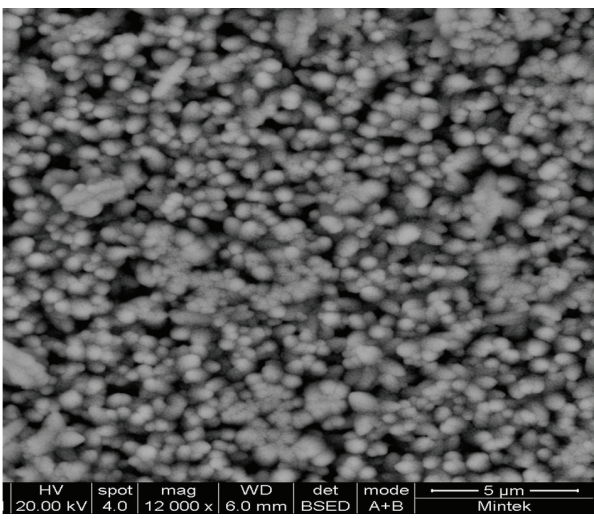

(a)

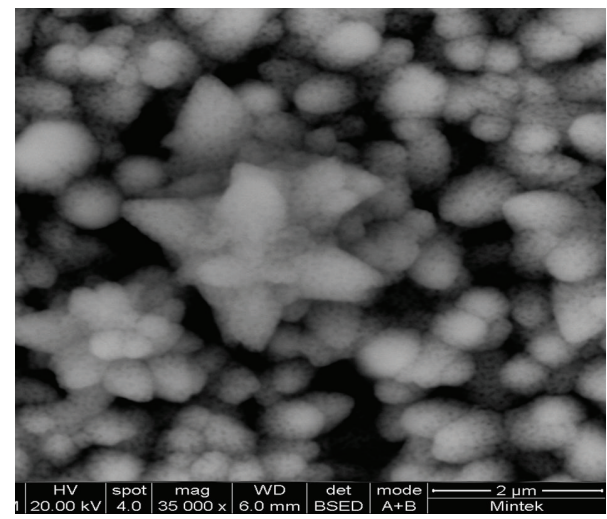

(b)

FIGURE 2: SEM image of undoped $\mathrm{ZnO}$ (a) with magnification $\times 12000$ and (b) with magnification $\times 35000$.

where $\mathrm{TC}(h k l)$ is the texture coefficient, $n$ is the number of diffraction peaks considered, $I(h k l)$ is the measured Xray intensity, and $I_{o}(h k l)$ is the corresponding recorded intensity according to JCPDS card. $I_{o}(h k l)$ represents the Xray intensities from standard $\mathrm{ZnO}$ powder with randomly oriented grains or with no preferred orientation (JCPDS). Since the diffraction peaks corresponding to (102), (110), and (103) appear with low relative intensities, the first three diffraction peaks corresponding to ((100), (002), and (101)) were considered for calculating TC. The texture coefficient for the (002) orientation was found to be 2.292 for undoped $\mathrm{ZnO}$ and it increases to 2.327 for $\mathrm{Al}$-doped $\mathrm{ZnO}$ indicating improved crystallinity of the doped film along (002) plane. The value of the texture coefficient indicates the maximum preferred orientation of the film along the diffraction plane under consideration. The incorporation of $\mathrm{Al}$ in the films was verified by the EDAX result. Figure 4 shows the energy dispersive X-ray spectrum of AZO film. The spectrum reveals the presence of $\mathrm{Zn}, \mathrm{O}$, and $\mathrm{Al}$ elements in the deposited films. The silicon signal appears from the substrate.

Figure 2 shows the SEM micrograph of undoped $\mathrm{ZnO}$ film, while Figure 3 shows the SEM image for $1 \%$ AZO films. The incorporation of $\mathrm{Al}$ into the lattice affects the morphology as can be seen from the micrographs. Figure 2(a) shows SEM image at normal incidence with magnification $\times 12000$.
It is evident that the microstructure consists of many round shaped clearly defined grains covering the substrate surface more or less uniformly. However there is agglomeration in certain regions of the film which is clearly visible in the SEM image with magnification $\times 35000$ (Figure 2(b)) and articles with off spherical shape are observed in AZO film indicating that $\mathrm{Al}$ doping modifies the shape of the grains. Also the film appears to have less porosity compared to undoped $\mathrm{ZnO}$. Figure 3(b) shows the SEM image of the same film with magnification $\times 40000$. The microstructure formed is found to be uniform with compact interconnected grains. Thus incorporation of $\mathrm{Al}$ leads to a more continuous film having higher density compared to undoped $\mathrm{ZnO}$.

Electrical resistance measurement at $100^{\circ} \mathrm{C}$ shows a marked decrease in resistance due to $\mathrm{Al}$ incorporation. While undoped $\mathrm{ZnO}$ shows a resistance of $2.28 \mathrm{M} \Omega, 1 \% \mathrm{AZO}$ shows a resistance value of $0.189 \mathrm{M} \Omega$. Such decrease in resistance confirms the substitutional replacement of $\mathrm{Zn}^{2+}$ ions by $\mathrm{Al}^{3+}$ and subsequent enhancement of carrier density. Distribution of $\mathrm{Al}$ in the grains leading to interconnected grains and a more continuous film also might contribute to the lowering of resistance by enhancing the mobility of charge carriers.

Figure 5 shows the percent sensitivity $(S \%)$ as a function of operating temperature in presence of $1.6 \mathrm{vol} \%$ LPG in air. This value corresponds to $80 \%$ LEL (lower explosive limit) 


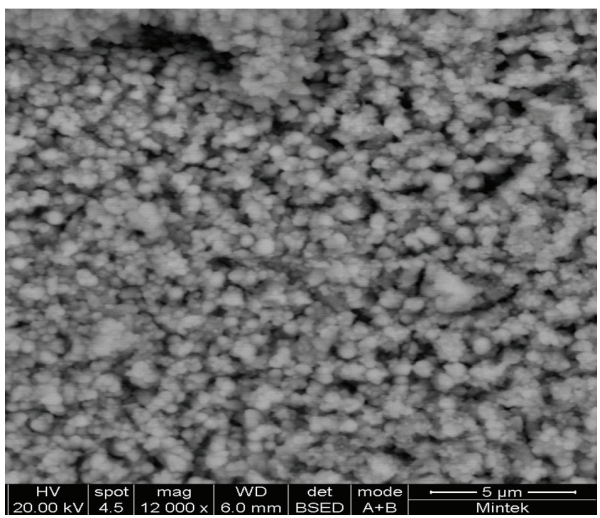

(a)

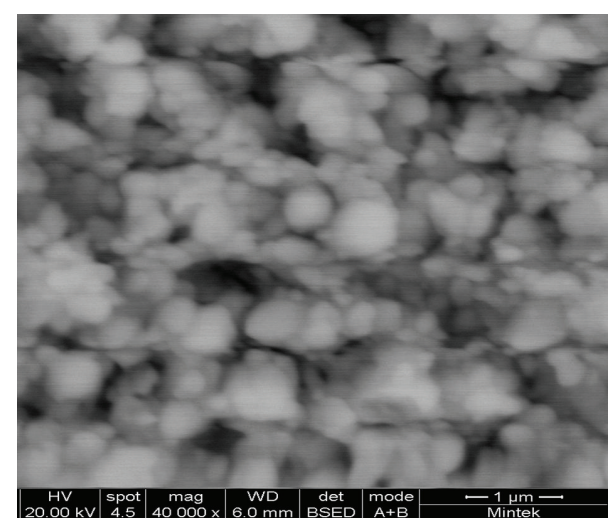

(b)

FIGURE 3: SEM image of $1 \%$ AZO film (a) with magnification $\times 12000$ and (b) with magnification $\times 40000$.

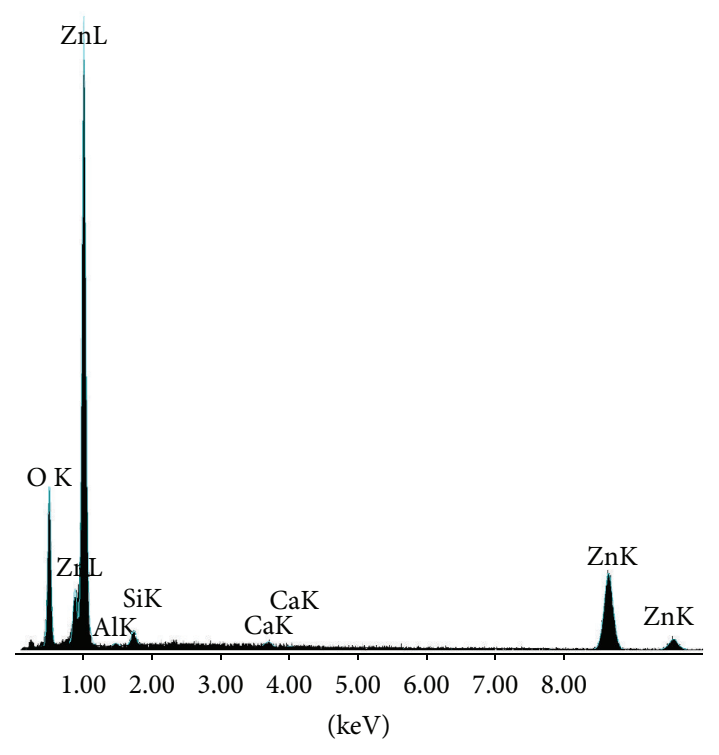

FIGURE 4: EDX pattern of AZO film.

of LPG in air. Butane $\left(\mathrm{C}_{4} \mathrm{H}_{10}\right)$ has a LEL of $1.6 \mathrm{vol} \%$ and propane $\left(\mathrm{C}_{3} \mathrm{H}_{8}\right)$ has a LEL of $2.1 \mathrm{vol} \%$. Thus the LEL of LPG is generally taken to be $2 \mathrm{vol} \%$. The exposure time to the target gas was 15 minutes. It is observed that compared to undoped $\mathrm{ZnO}$ film, Al-doping enhances the sensitivity of the films at all temperatures. The sensitivity increases with increasing temperature of the sensor element, reaches a peak value, and then decreases again. The peak sensitivity for AZO film was observed at $325^{\circ} \mathrm{C}$ and the value of maximum sensitivity was $87 \%$. Similar characteristic has been reported by Sahay and Nath [22] with peak sensitivity of $\sim 89 \%$ at $325^{\circ} \mathrm{C}$ in presence of $1 \mathrm{vol} \%$ LPG. Figure 6 shows sensing characteristics of the undoped and Al-doped film in presence of $1.6 \mathrm{vol} \% \mathrm{LPG}$ in air at $325^{\circ} \mathrm{C}$. The plot of resistance ratio $R_{\text {gas }} / R_{\text {air }}$ against time is shown in the figure. Faster response (short response time) is given by $\mathrm{Al}$-doped $\mathrm{ZnO}$ compared to undoped $\mathrm{ZnO}$ film.

The gas sensing mechanism normally accepted for semiconductor sensors assumes that the oxygen adsorbed on the

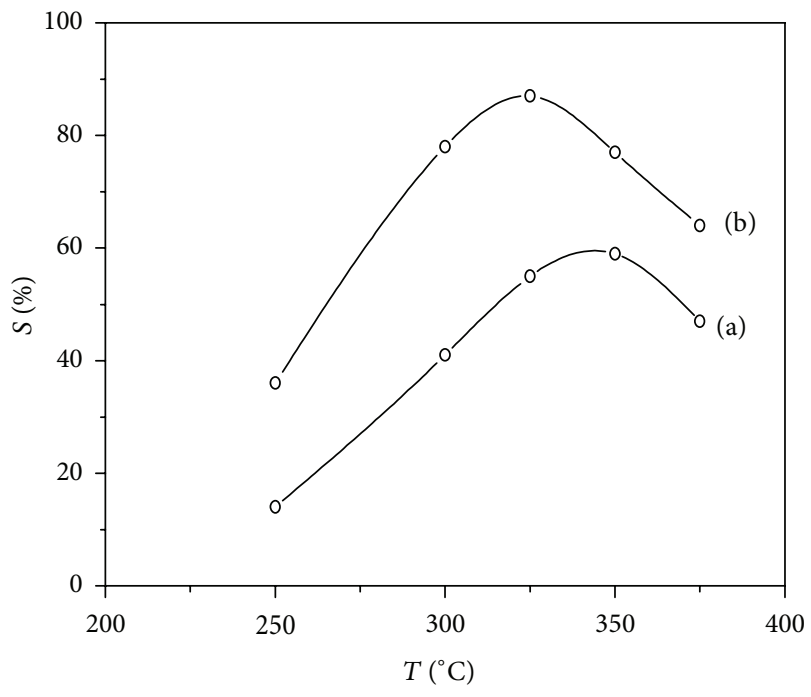

FIGURE 5: Sensitivity versus operating temperature of (a) undoped $\mathrm{ZnO}$ and (b) $1 \%$ AZO film.

surface of the oxide traps some of the conduction electrons and thus decreases the material's conductivity [23]. The surface adsorbed oxygen species thus becomes negatively charged chemisorbed species $\left(\mathrm{O}_{2}^{-}, \mathrm{O}^{-}\right.$or $\left.\mathrm{O}^{2-}\right)$ and acts as reaction centers for gas molecules. When reduction gas molecules come into contact with this surface, they may interact with this chemisorbed oxygen species, leading to an inverse charge transference [19]. Upon the return of the electrons to the conduction band, conductivity increases. The reaction mechanism for LPG (containing the hydrocarbons propane and butane) with surface adsorbed species leading to the final products $\mathrm{CO}_{2}$ and $\mathrm{H}_{2} \mathrm{O}$ is quite complicated and proceeds through several intermediate steps $[22,24]$.

Enhancement of sensitivity with operating temperature has been attributed to increased speed of chemical reaction between the gas molecules and chemisorbed oxygen species [21]. At high temperatures, gas molecules have enough thermal energy to react with the chemisorbed species. However 


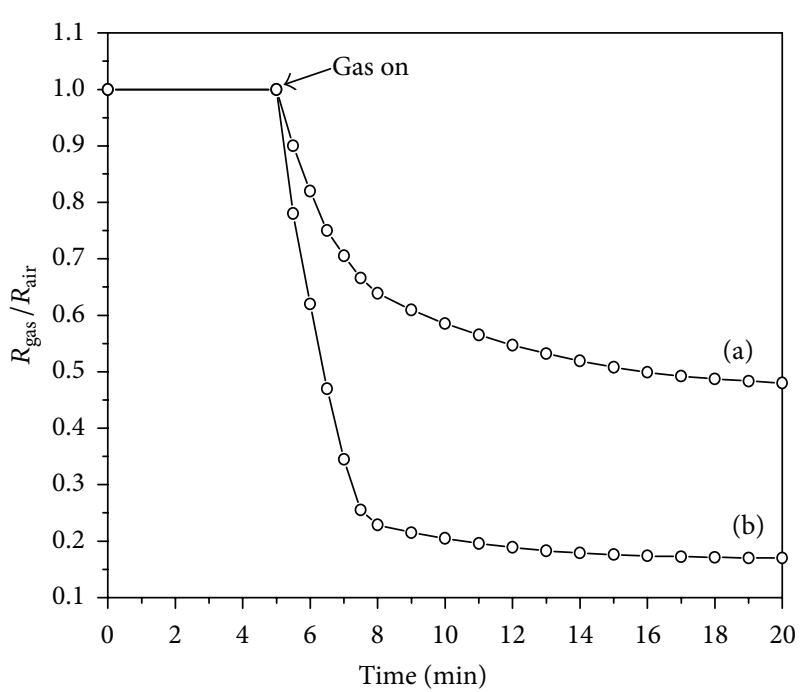

FIGURE 6: Sensing characteristics in presence of $1.6 \mathrm{vol} \%$ LPG in air at $325^{\circ} \mathrm{C}$ for (a) undoped $\mathrm{ZnO}$ and (b) $1 \% \mathrm{AZO}$ film.

the appearance of peak sensitivity at $325^{\circ} \mathrm{C}$ has not been explained. It has been established that the nature of the chemisorbed species is a function of temperature [25]. While $\mathrm{O}_{2}{ }^{-}$is considered to be the prominent chemisorbed species upto $500 \mathrm{~K}$, for temperatures higher than $500 \mathrm{~K}, \mathrm{O}^{-}$is the predominant species. As is evident from experimental observation, reasonable sensitivity appears for temperatures higher than $500 \mathrm{~K}$ where the predominant species is $\mathrm{O}^{-}$. With increase in temperature, the reaction $\mathrm{O}_{2}{ }^{-}+e \rightarrow 2 \mathrm{O}^{-}$, leading to the formation of $\mathrm{O}^{-}$species proceeds at a faster rate, thereby increasing the density of $\mathrm{O}^{-}$species. Since these are the active sites for reaction with gas molecules, the sensitivity increases with temperature. This process must accompany the process of enhancement of thermal energy of the gas molecules with temperature in order to explain the reduction of sensitivity above a particular temperature. With further increase in operating temperature a gradual change of the adsorbed species from $\mathrm{O}^{-}$to $\mathrm{O}^{2-}$ takes place according to the reaction $\mathrm{O}^{-}+e \rightarrow \mathrm{O}^{2-}$. The latter species, despite having high reactivity, is unstable and can go into the lattice as lattice oxygen $[25,26]$. Thus we can presume that at temperatures above $325^{\circ} \mathrm{C}$, the number of chemisorbed species available for surface activity is lowered. This lack in number of chemisorbed species can slow down the catalytic oxidation reaction and leads to a decrease in net yield of conduction electrons and hence sensitivity.

The enhancement of sensitivity due to $\mathrm{Al}$ incorporation might be due to increase in electron concentration (carrier density) as has been observed in resistance measurement as well as less porosity in the film as has been observed in SEM measurements. Such increase in conduction electron concentration leads to an increased density of surface active chemisorbed species which are the reaction centers for gassurface reaction. Also more porous film allows gas molecules to penetrate inside the film and the resistance reduction process continues for a longer time. This delays the attainment of equilibrium resistance value in presence of target gas and increases response time as has been observed for undoped film in the present work.

\section{Conclusions}

Undoped and Al-doped $\mathrm{ZnO}$ thin film could be successfully synthesized from ammonium zincate complex for the first time by SILAR technique. Apart from being an inexpensive and simple technique, the method uses milder reaction conditions than those employed by most chemical methods proposed in the literature. Al incorporation increases the growth rate of the film. XRD spectra showed that the films have hexagonal structure with preferred c-axis orientation. Texture coefficient of (002) plane increases due to $\mathrm{Al}$ incorporation indicating improved crystallinity along c-axis. SEM micrograph shows round shaped particles for pure $\mathrm{ZnO}$. $\mathrm{Al}$ doping modifies the shape of the grains to off spherical ones. AZO film also appears to have high density (i.e., less porosity) compared to undoped $\mathrm{ZnO}$ and consists of compact interconnected grains leading to a more continuous film. This fact along with substitutional replacement of divalent $\mathrm{Zn}^{2+}$ by trivalent $\mathrm{Al}^{3+}$ decreases the film resistance. The sensitivity of the films increases with temperature, reaches a maximum, and then decreases. The phenomena can be explained by the change in nature of chemisorbed species with temperature as well as their number density. Significantly high sensitivity of $87 \%$ with a reasonably fast response is observed for AZO film in presence of $1.6 \mathrm{vol} \% \mathrm{LPG}$ in air.

\section{Acknowledgment}

P. Mitra gratefully acknowledges CSIR (Council of Scientific and Industrial research, New Delhi, India) for providing some financial support for the work in the form of a research project (no. 03 (1195)/11/EMR-II).

\section{References}

[1] S. H. Jeong, B. N. Park, D.-G. Yoo, J.-H. Boo, and D. Jung, "Al-ZnO thin films as transparent conductive oxides: synthesis, characterization, and application tests," Journal of the Korean Physical Society, vol. 50, no. 3, pp. 622-625, 2007.

[2] K. V. Gurav, V. J. Fulari, U. M. Patil, C. D. Lokhande, and O.S. Joo, "Room temperature soft chemical route for nanofibrous wurtzite $\mathrm{ZnO}$ thin film synthesis," Applied Surface Science, vol. 256, no. 9, pp. 2680-2685, 2010.

[3] B. Baruwati, D. K. Kumar, and S. V. Manorama, "Hydrothermal synthesis of highly crystalline $\mathrm{ZnO}$ nanoparticles: a competitive sensor for LPG and EtOH," Sensors and Actuators B, vol. 119, no. 2, pp. 676-682, 2006.

[4] T. M. Barnes, J. Leaf, C. Fry, and C. A. Wolden, "Room temperature chemical vapor deposition of c-axis $\mathrm{ZnO}$," Journal of Crystal Growth, vol. 274, no. 3-4, pp. 412-417, 2005.

[5] S. Tewari and A. Bhattacharjee, "Structural, electrical and optical studies on spray-deposited aluminium-doped $\mathrm{ZnO}$ thin films," Pramana, vol. 76, no. 1, pp. 153-163, 2011. 
[6] S. Y. Lee, Y. Li, J.-S. Lee et al., "Effects of chemical composition on the optical properties of $\mathrm{Zn}_{1-x} \mathrm{Cd}_{x} \mathrm{O}$ thin films," Applied Physics Letters, vol. 85, no. 2, pp. 218-220, 2004.

[7] H. T. Cao, Z. L. Pei, J. Gong, C. Sun, R. F. Huang, and L. S. Wen, "Preparation and characterization of $\mathrm{Al}$ and $\mathrm{Mn}$ doped $\mathrm{ZnO}$ (ZnO: (Al, Mn)) transparent conducting oxide films," Journal of Solid State Chemistry, vol. 177, no. 4-5, pp. 1480-1487, 2004.

[8] K. Yim and C. Lee, "Optical properties of Al-doped $\mathrm{ZnO}$ thin films deposited by two different sputtering methods," Crystal Research and Technology, vol. 41, no. 12, pp. 1198-1202, 2006.

[9] K. Yamaya, Y. Yamaki, H. Nakanishi, and S. Chichibu, "Use of a helicon-wave excited plasma for aluminum-doped $\mathrm{ZnO}$ thinfilm sputtering," Applied Physics Letters, vol. 72, no. 2, pp. 235237, 1998.

[10] S. P. Shrestha, R. Ghimire, J. J. Nakarmi et al., "Properties of $\mathrm{ZnO}: \mathrm{Al}$ films prepared by spin coating of aged precursor solution," Bulletin of the Korean Chemical Society, vol. 31, no. 1, pp. 112-115, 2010.

[11] H.-M. Zhou, D.-Q. Yi, Z.-M. Yu, L.-R. Xiao, and J. Li, "Preparation of aluminum doped zinc oxide films and the study of their microstructure, electrical and optical properties," Thin Solid Films, vol. 515, no. 17, pp. 6909-6914, 2007.

[12] H. Sato, T. Minami, S. Takata, T. Miyata, and M. Ishii, "Low temperature preparation of transparent conducting $\mathrm{ZnO}: \mathrm{Al}$ thin films by chemical beam deposition," Thin Solid Films, vol. 236, no. 1-2, pp. 14-19, 1993.

[13] W. Tang and D. C. Cameron, "Electrical resistivity of nanocrystalline Al-doped zinc oxide films as a function of Al content and the degree of its segregation at the grain boundaries," Thin Solid Films, vol. 238, pp. 83-87.

[14] J. Mass, P. Bhattacharya, and R. S. Katiyar, "Effect of high substrate temperature on $\mathrm{Al}$-doped $\mathrm{ZnO}$ thin films grown by pulsed laser deposition," Materials Science and Engineering B, vol. 103, no. 1, pp. 9-15, 2003.

[15] A. E. Rakhshani, "Al-doped zinc oxide films grown by successive chemical solution deposition," Applied Physics A, vol. 92, no. 2, pp. 413-416, 2008.

[16] P. Mitra, "Preparation of $\mathrm{ZnO}$ film on p-Si substrate and I-V characteristics of p-Si/n-ZnO," Material Science Research India, vol. 8, pp. 197-202, 2011.

[17] P. Mitra and J. Khan, "Chemical deposition of $\mathrm{ZnO}$ films from ammonium zincate bath," Materials Chemistry and Physics, vol. 98, no. 2-3, pp. 279-284, 2006.

[18] S. Mondal and P. Mitra, "Preparation of cadmium doped ZnO thin films by SILAR and their characterization," Bulletin of Materials Science, vol. 35, pp. 751-757, 2012.

[19] S. S. Kale, R. S. Mane, H. M. Pathan, A. V. Shaikh, O.-S. Joo, and S.-H. Han, "Preparation and characterization of ZnTe thin films by SILAR method," Applied Surface Science, vol. 253, no. 9, pp. 4335-4337, 2007.

[20] Joint Committee on Powder Diffraction standards, "Inorganic," B. Post, S. Weissmann, and H. F. McMurdie, Eds., Card No. 361451, International Centre for Diffraction Data, Swarthmore, Pa, USA, 1990.

[21] C. S. Prajapati and P. P. Sahay, "Growth, structure and optical characterization of Al-doped $\mathrm{ZnO}$ nanoparticle thin films," Crystal Research and Technology, vol. 46, no. 10, pp. 1086-1092, 2011.

[22] P. P. Sahay and R. K. Nath, "Al-doped zinc oxide thin films for liquid petroleum gas (LPG) sensors," Sensors and Actuators B, vol. 133, no. 1, pp. 222-227, 2008.
[23] S. M. Chou, L. G. Teoh, W. H. Lai, Y. H. Su, and M. H. Hon, "Thin film gas sensor for detection of ethanol," Vapor Sensors, vol. 6, pp. 1420-1427, 2006.

[24] V. R. Shinde, T. P. Gujar, and C. D. Lokhande, "LPG sensing properties of $\mathrm{ZnO}$ films prepared by spray pyrolysis method: effect of molarity of precursor solution," Sensors and Actuators $B$, vol. 120, no. 2, pp. 551-559, 2007.

[25] J. C. Simpson and J. F. Cordaro, "Characterization of deep levels in zinc oxide," Journal of Applied Physics, vol. 63, no. 5, pp. 1781$1783,1988$.

[26] G. Heiland and D. Kohl, "Chemical sensor technology," in Ceramics for Chemical Sensing, T. Seiyama, Ed., vol. 1, p. 15, KodanshaSpringer, Tokyo, Japan, 1988. 

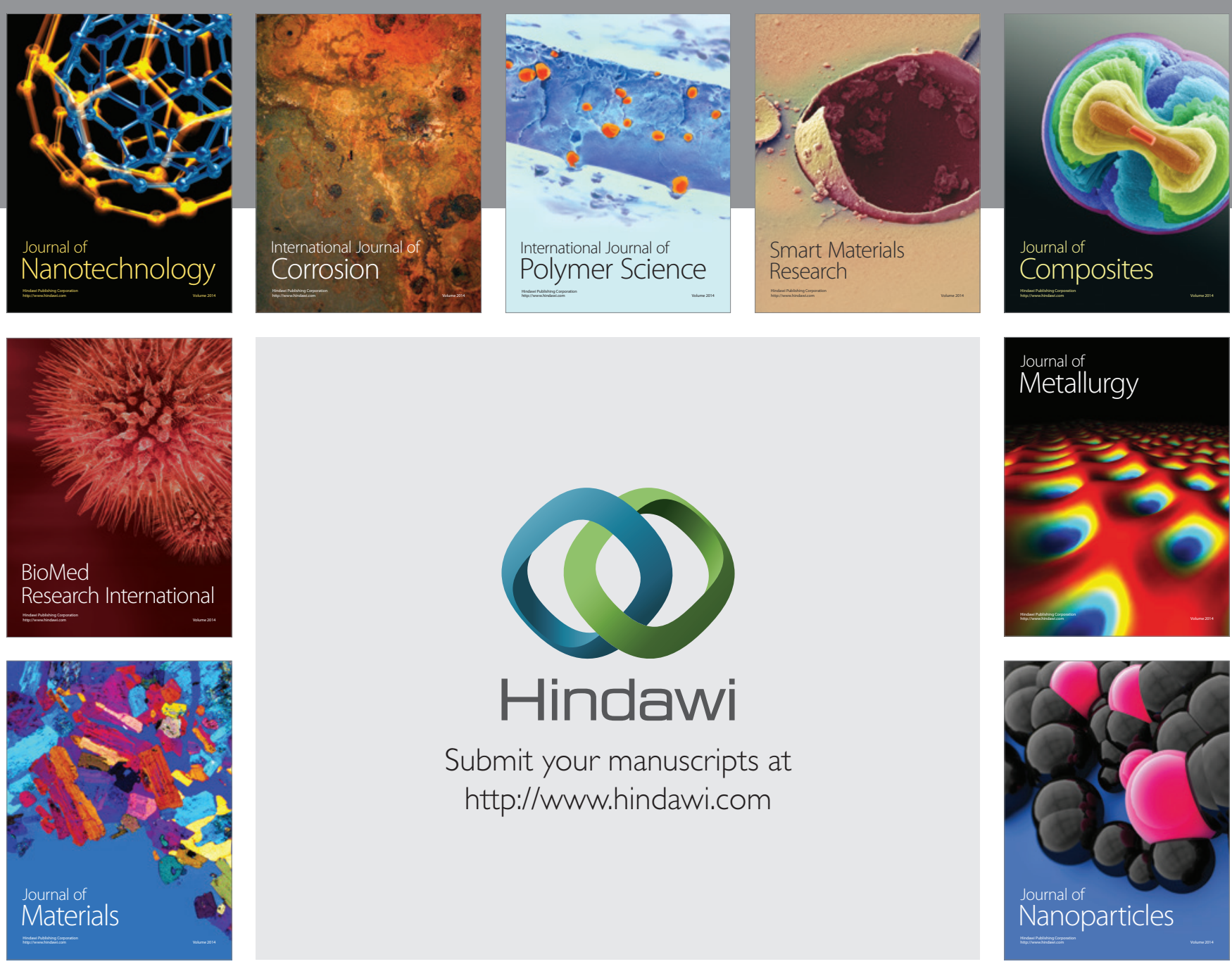

Submit your manuscripts at http://www.hindawi.com
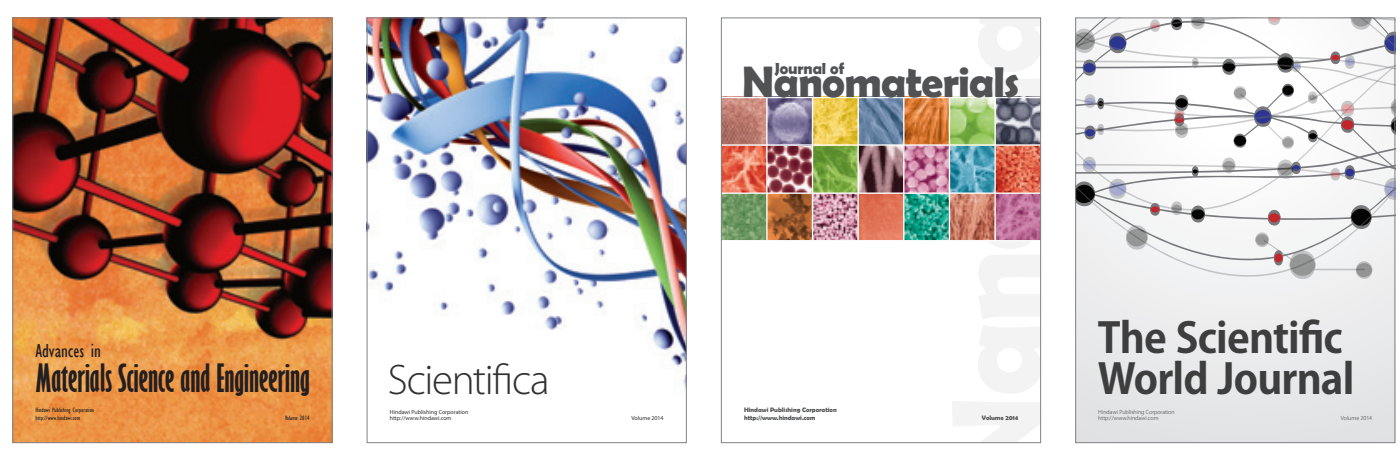

\section{The Scientific World Journal}
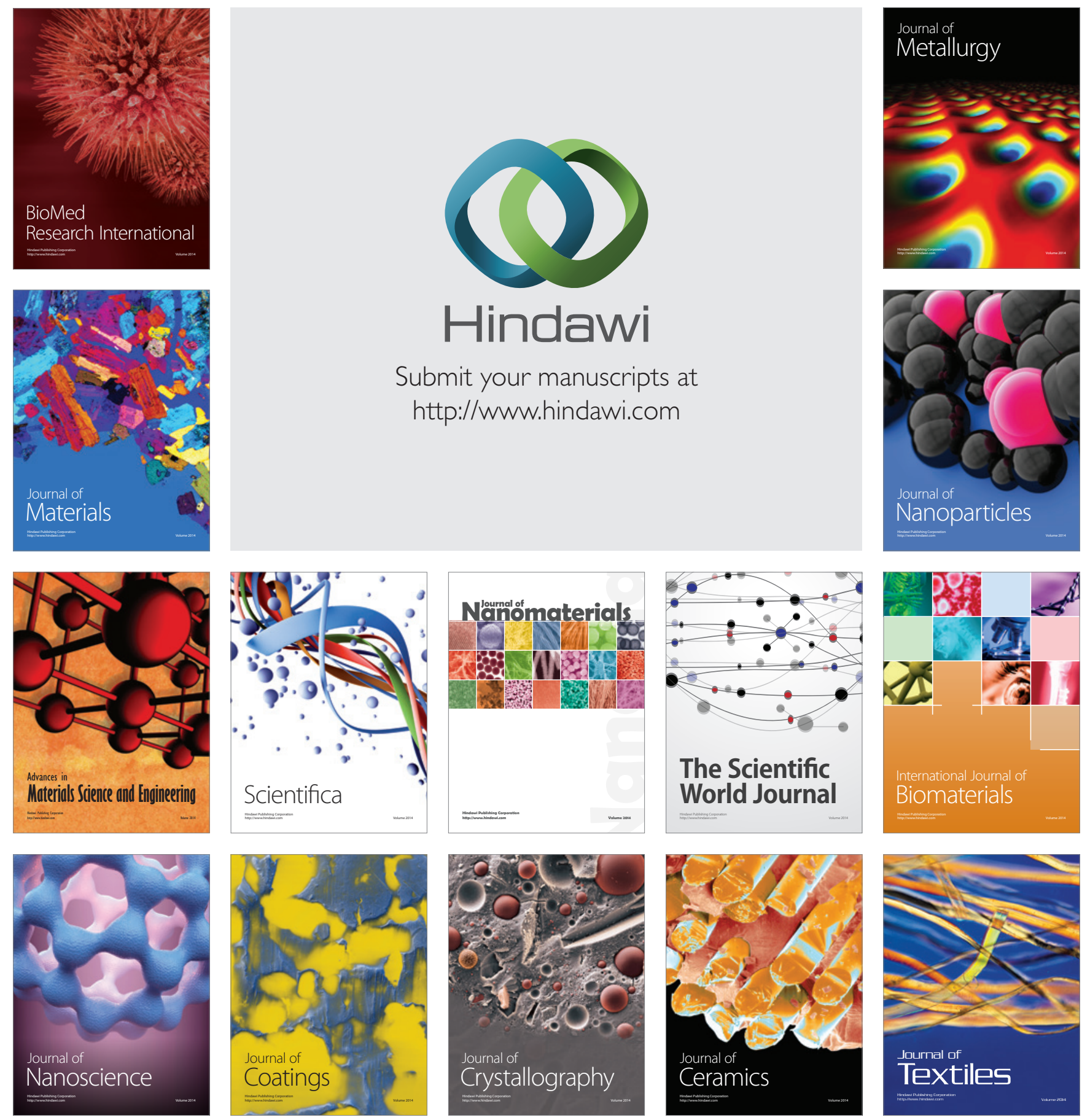